\title{
EXPERIMENTAL RESEARCH IN IRRIGATION BY CONDENSATION IN SOLARIUM
}

\author{
Costin Mircea, Dragos Manea, Eugen Marin, Marinela Mateescu \\ National Institute of Research-Development for Machines and Installations Designed to Agriculture \\ and Food Industry, Romania \\ costinmircea@yahoo.com,manea_dragos_05@yahoo.com,marin_43eu@yahoo.com, \\ marinelamateescu@yahoo.com
}

\begin{abstract}
Irrigation is one of the most important technological sequences with a strong impact on the physical characteristics of the soil through the wetting process with positive implications in plant metabolism. Unexpected but significant, climate change exposes crops to cold or heat that affect agriculture and product quality, leading to a massive investment to control the plant's climate with fossil fuels. These global negative trends present a major technological challenge and a need to invest in new technology solutions to replace the traditional irrigation technology with an innovative one. Irrigation by condensation is an inexhaustible water resource by combination of high air relative moisture, air temperature and low water temperature flowing through a closed loop system. This paper presents the results of the experimental researches of irrigation by condensation installation, which was designed and manufactured by INMA Bucharest, the installation being located inside a solarium. The experimental researches aimed to compare the soil moisture regime registered on three soil depth levels in two air relative moisture conditions for two types of pipes, copper and PEHD. The moisture that condenses on the pipes' surface flows by gravity into the soil and was measured in five measuring points located on two diagonals of the experimental plot. The results showed that the soil moisture at the sampling points for the copper pipes was higher than for the PEHD pipes, in both cases for the air relative moisture. In other words, the amount of condensed water extracted from the air on the surface of the copper pipes was higher than with the PEHD pipes. At the same time, significantly higher values for soil moisture were obtained for the copper pipes when the relative humidity of the air was $60 \%$. Conclusions from the experimental research have highlighted that in many cases no additional irrigation is required to maintain plant survival and food production.
\end{abstract}

Keywords: irrigation, condensation, moisture, solarium.

\section{Introduction}

Irrigation by condensation is an inexhaustible resource of water for irrigation, due to combination of high air relative moisture, air temperature and low temperature of water circulating through a closed loop system. Irrigation by condensation is designed primarily for arid and semi-arid areas, where groundwater is deep and fresh water sources are rare. Worldwide, studies on irrigation by condensation were made over time by several researchers [1-3].

Edward Linacre, the winner of the James Dyson grand prize for the year 2011 invented a device that can provide water for farms by mimicking the Namib beetle, which lives in the most arid area on the planet, and provides itself with fresh water by condensing moisture from the air on its hydrophilic back and absorbing it in early mornings [4]. He made a pumping device that pushes the surrounding air with moisture under the ground to pass through the pipe network, where the moisture will start condensing on the internal walls of the pipes, then, the water drops will leak from the pipes directly to the roots of plants in that field. The key principle of extracting moisture from air is based on the dew point phenomenon, which is the temperature, where the air moisture will condense forming water [5]. This principle is used in the water collecting inventions, where a cold surface is used to make the warmer humid air reach the dew point and form water drops on it in order to collect this water to be used for irrigation purposes.

Alnaser and Barakat [6], in Bahrain, found that the most favourable conditions for dew condensation persist at dawn. The maximum amount of dew water could be collected in January and the least in August. They tested three condensation surfaces: aluminium, glass and polyethylene foils. The average quantity of dew collected on these surfaces was $1.3,0.8$ and $0.3 \mathrm{~kg} \cdot \mathrm{m}^{-2}$ per hour, respectively.

Beysens et al. [7] tested in Grenoble (France) an inexpensive radiative condenser for collecting atmospheric vapour (dew). The surface temperature measurements were correlated with the meteorological data (wind velocity, air temperature) and compared to the corresponding surface 
temperature of a horizontal plexiglas reference plate located nearby. The condenser surface was a rectangular foil $\left(1 \times 0.3 \mathrm{~m}^{2}\right)$ made of $\mathrm{TiO}_{2}$ and $\mathrm{BaSO}_{4}$ microspheres embedded in polyethylene. The foil has an angle $\theta$ with respect to horizontal. The underside of the device, thermally isolated, faces the direction of the dominant nocturnal wind. Both the $2 \mathrm{D}$ numerical simulation of the air circulation around the foil and experimental measurements show that the angle $\theta=30^{\circ}$ is a good compromise between weak wind influence, large light-emission solid angle and easy drop collection. The study was conducted from November 25, 1999 to January 23, 2001. In comparison to the reference plate, it was found that the water yield can be increased by up to $20 \%$ and water collection greatly facilitated.

Most recently, Tomaszkiewicza et al. [8] compared reforestation and agriculture water demands to measured dew volumes to assess the feasibility of irrigation from dew harvesting. Field data collected from dew condensers showed that $43 \%$ of nights produced dew during the dry season (April-October) with average nightly dew yield of $0.13 \mathrm{l} \cdot \mathrm{m}^{-2}$ of the condensing surface and a maximum yield of $0.46 \mathrm{l} \cdot \mathrm{m}^{-2} \cdot \mathrm{day}^{-1}$. The experimental results showed that dew events are more frequent than precipitation events and harvested dew can significantly impact diurnal soil moisture $(>3 \%)$ during evenings with above average nightly dew yields $\left(>0.21 \cdot \mathrm{m}^{-2} \cdot \mathrm{day}^{-1}\right)$. They demonstrated that harvesting and storing dew using reasonable condensing areas $\left(2 \mathrm{~m}^{2}\right)$ can be sufficient to irrigate tree seedlings, typically requiring $4.51 \cdot$ seedling $^{-1}$ every $30-40$ days. Moreover, these low-cost stand-alone systems can prevail in remote locations, where infrastructure and traditional water resources are limited.

However, the attempts to get water from air in the most arid areas in the world did not stop. More ideas are coming up every day for sustainable, clean, cheap, and renewable fresh water solutions, providing people of the poor arid areas with reliable fresh water sources.

This paper presents the results of the experimental researches of irrigation by condensation installation, which was designed and manufactured by the National Institute of Research Development for Machines and Installations Designed to Agriculture and Food Industry - INMA Bucharest.

\section{Materials and methods}

The climatic conditions in this area $\left(44^{\circ} 29^{\prime} 58.9^{\prime \prime} \mathrm{N}, 26^{\circ} 04^{\prime} 14.3^{\prime \prime} \mathrm{E}\right.$, altitude $\left.100-115 \mathrm{~m}\right)$, were the experiments were carried out, are characterized by warm summers (average temperature $22-23{ }^{\circ} \mathrm{C}$ ), big differences from day to night and $595 \mathrm{~mm}$ total annual precipitation.

Irrigation by condensation installation was located inside a solarium. The solarium dimensions were $30 \mathrm{~m}$ length and $10 \mathrm{~m}$ width, the height was $5.3 \mathrm{~m}$ to the ridge and $2.95 \mathrm{~m}$ to the gutter. The entire surface of the solarium was covered with air-cushion double polyethylene foil with the following properties: UV resistant, $600 \%$ elongation, anti-dust outer layer, $0.15 \mathrm{~mm}$ thick and $90 \%$ transparency.

Irrigation by condensation installation presented in Fig. 1 was mainly composed by: insulated water tank of 5001 capacity; water chiller TK 500 with flow rates between 450 and $750 \mathrm{l} \cdot \mathrm{h}^{-1}$ and the digital water temperature set up between $0{ }^{\circ} \mathrm{C}$ and $35^{\circ} \mathrm{C}$; circulation pump UPS 15-50 CIL 130 and a network of blind copper and PEHD (polyetilene) pipes of $25 \mathrm{~mm}$ diameter and $15 \mathrm{~m}$ lenght, mounted alternatively in a closed loop, placed on the ground surface, through which the cooled water was recirculated. The water filling of the installation was done once and then, only if was necessary, in case of possible loss. The air humidity that condenses on the external surface of the pipes flows by gravity into the soil, irrigating and cooling the plant roots.

The surface of the experimental plot ABCD (Figure 2) was $45 \mathrm{~m}^{2}$ (15 m length and $3 \mathrm{~m}$ width). The soil moisture was measured in 5 measuring points (P1-1'... P5-5') located on the two diagonals, $\mathrm{AC}$ and $\mathrm{BD}$, of the experimental plot, for each pipe type (copper and PEHD). Water was cooled in the insulated water tank to below dew point temperatures and was pumped in the network pipes.

The moisture obtained on the external surface of the pipes was evaluated by measuring the local soil moisture in the immediate vicinity of the pipes, using a HH2 Delta-T Devices Moisture Meter. Relative moisture and air temperature inside the solarium were measured using a $0-10 \mathrm{Vcc}$ sensor, readings being read on the display of a programmable controller. 


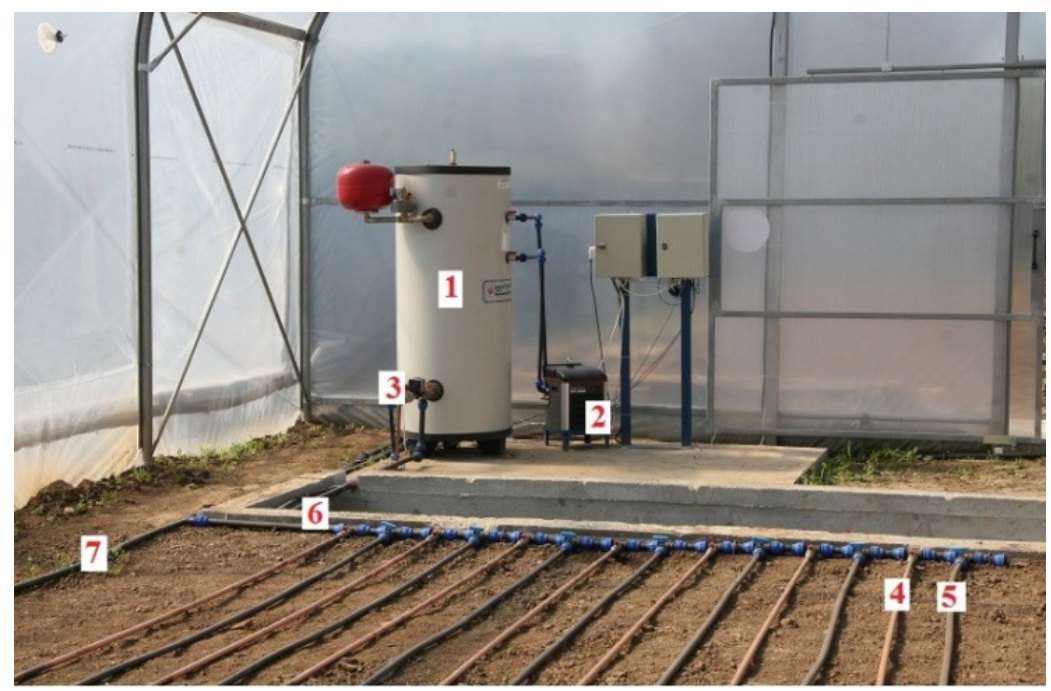

Fig. 1. Irrigation by condensation installation: 1 - water tank; 2 -water chiller; 3 - circulation pump; 4 - copper pipes; 5 - PEHD pipes; 6 - water inlet pipe; 7 - water return pipe

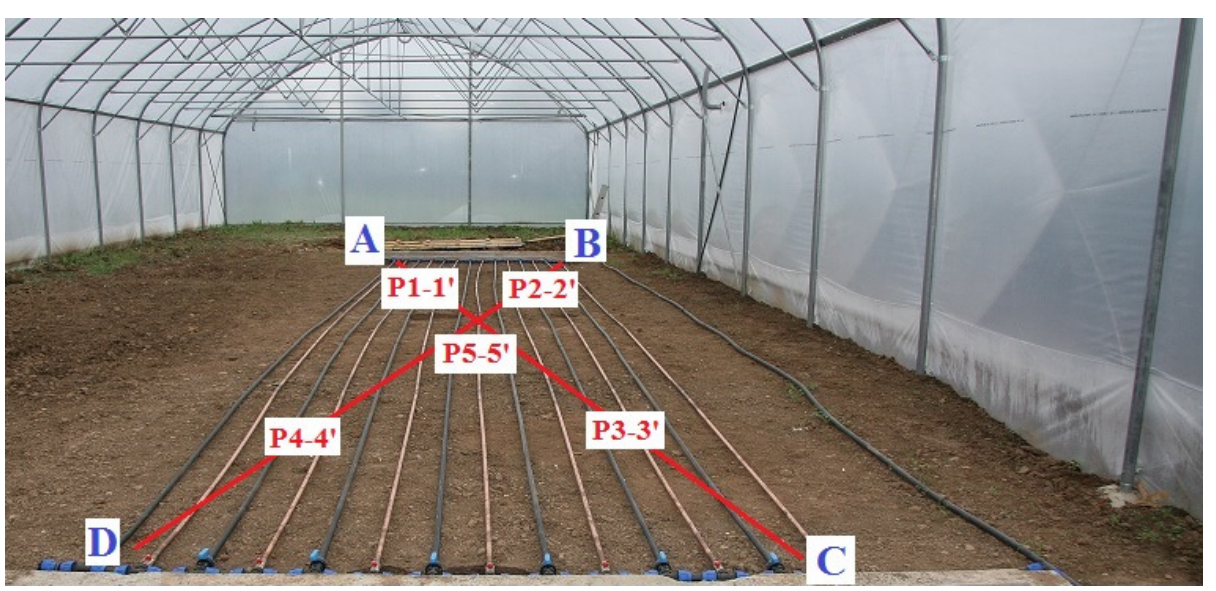

Fig. 2. Outline of experimental plot with moisture sampling points

In order to obtain a sufficient amount of water through condensation, we must take into account the soil moisture, air relative moisture and the air temperature. Regarding the soil moisture during the vegetation period, vegetables can be divided into the following categories: vegetables with very high water requirements (cauliflower, broccoli, cabbage), with large requirements (pumpkin, carrot, cucumber, parsley, pastry, celery, carrot), with moderate requirements (eggplants, onions, radishes, tomatoes, peppers, peas) and low requirements (beans, leeks, red beets). In terms of the air moisture, vegetables can be divided into several categories: vegetables with high humidity (about 90\%) cucumbers, petiole celery with moderate humidity (about $70 \%$ ) - beets, carrots, potatoes, cabbage; with low humidity (60-70\%) - peppers, eggplants, garden beans, tomatoes; with low humidity (pumpkin, melons) [9].

The experimental researches in this study aimed to compare the soil moisture regime registered on three soil depth levels $(0-5 \mathrm{~cm} ; 5-10 \mathrm{~cm} ; 10-20 \mathrm{~cm})$ in two air relative moisture conditions $(80 \%$ and $60 \%$ ) for the two types of pipes, copper and PEHD. The air temperature inside the solarium was $30{ }^{\circ} \mathrm{C}$.

\section{Results and discussion}

To assess the impact of condensation irrigation on the soil moisture, it was necessary to determine a control sample where the soil was not irrigated, as it can be seen from Table 1.

Thereafter, the need for statistical processing at both sampling points and sampling depths has emerged to highlight the variation in the soil moisture. The statistical indicators determined were the 
standard deviation $\sigma$ and the coefficient of variation $C_{v},[10]$. The results are presented in Table 2 and Table 3

Table 1

Initial state of the soil, not irrigated

\begin{tabular}{|c|c|c|c|c|c|c|c|c|c|c|}
\hline \multirow{3}{*}{$\begin{array}{c}\text { Depth, } \\
\text { cm }\end{array}$} & \multicolumn{10}{|c|}{ Soil moisture, \% } \\
\hline & \multicolumn{5}{|c|}{ Copper pipes } & \multicolumn{5}{|c|}{ PEHD pipes } \\
\hline & $\mathrm{P} 1$ & $\mathrm{P} 2$ & P3 & $\mathrm{P} 4$ & P5 & P1' & P2' & P3' & P4' & P5' \\
\hline $0-5$ & 12.3 & 11.4 & 10.4 & 12.3 & 11.6 & 12.4 & 11.2 & 10.2 & 12.1 & 11.0 \\
\hline $5-10$ & 13.6 & 11.9 & 12.5 & 14.4 & 12.8 & 13.7 & 12.0 & 11.8 & 14.2 & 12.2 \\
\hline $10-20$ & 15.5 & 12.6 & 14.7 & 15.0 & 13.7 & 15.3 & 12.6 & 13.4 & 14.8 & 13.0 \\
\hline
\end{tabular}

Table 2

Statistical indicators at sampling points and sampling depths for soil moisture in $\%$, when the relative moisture of the air was $80 \%$

\begin{tabular}{|c|c|c|c|c|c|c|c|c|c|c|}
\hline \multirow{2}{*}{ Depth, cm } & \multicolumn{4}{|c|}{ Copper pipes } & \multicolumn{5}{c|}{ PEHD pipes } \\
\cline { 2 - 12 } & P1 & P2 & P3 & P4 & P5 & P1' & P2' & P3' & P4' & P5' \\
\hline $0-5$ & 26.7 & 26.7 & 28.8 & 28.4 & 27.4 & 24.5 & 27.8 & 25.6 & 24.9 & 28.2 \\
\hline $5-10$ & 25.3 & 26.1 & 25.3 & 26.4 & 25.5 & 21.6 & 25.7 & 24.9 & 22.9 & 26.1 \\
\hline $10-20$ & 24.2 & 24.7 & 23.9 & 24.0 & 24.4 & 22.2 & 22.7 & 23.7 & 22.6 & 23.0 \\
\hline Average & 25.4 & 25.8 & 26.0 & 26.2 & 25.7 & 22.7 & 25.4 & 24.7 & 23.4 & 25.7 \\
\hline Standard deviation, $\sigma$ & 2.05 & 1.75 & 2.51 & 2.83 & 1.81 & 1.28 & 2.88 & 1.53 & 1.03 & 2.92 \\
\hline $\begin{array}{c}\text { Coefficient of } \\
\text { variation } C_{v}, \%\end{array}$ & 8.34 & 6.99 & 9.90 & 11.24 & 7.20 & 5.58 & 11.78 & 6.34 & 4.39 & 11.78 \\
\hline
\end{tabular}

Table 3

Statistical indicators at sampling points and sampling depths for soil moisture in $\%$, when the relative moisture of the air was $60 \%$

\begin{tabular}{|c|c|c|c|c|c|c|c|c|c|c|}
\hline \multirow{2}{*}{ Depth, cm } & \multicolumn{4}{|c|}{ Copper pipes } & \multicolumn{5}{c|}{ PEHD pipes } \\
\cline { 2 - 12 } & P1 & P2 & P3 & P4 & P5 & P1' & P2 & P3' & P4' & P5 $^{\prime}$ \\
\hline $0-5$ & 16.6 & 18.7 & 18.5 & 15.4 & 11.5 & 14.0 & 13.6 & 11.7 & 14.0 & 13.2 \\
\hline $5-10$ & 20.2 & 19.8 & 20.8 & 16.0 & 14.0 & 15.3 & 13.0 & 14.7 & 15.7 & 13.5 \\
\hline $10-20$ & 20.4 & 23.5 & 21.7 & 17.4 & 16.0 & 16.5 & 16.9 & 17.9 & 15.5 & 14.6 \\
\hline Average & 19.06 & 20.6 & 20.3 & 16.2 & 13.8 & 15.2 & 14.5 & 14.7 & 15.06 & 13.7 \\
\hline Standard deviation, $\sigma$ & 4.31 & 6.52 & 1.93 & 1.27 & 2.60 & 1.62 & 1.90 & 2.77 & 0.76 & 1.05 \\
\hline $\begin{array}{c}\text { Coefficient of } \\
\text { variation, } C_{v}, \%\end{array}$ & 20.49 & 27.36 & 9.16 & 7.54 & 17.58 & 10.15 & 12.70 & 18.03 & 5.04 & 7.36 \\
\hline
\end{tabular}

Analyzing the data from Tables 2 and 3, it was observed that the determined values of the coefficient of variation are well below the value of $35 \%$ indicated in the specialized literature, so we conclude that the sampling sample is homogeneous and also the results as the average of soil moisture are statistically representative.

Another observation is that the soil moisture at the sampling points corresponding to the copper pipes was higher than for the PEHD pipes, both in the case, when the air relative moisture was $80 \%$ and when it was $60 \%$. In other words, the amount of condensed water extracted from the air on the surface of the copper pipes was higher than with the PEHD pipes. This is due to the very low thermal transfer coefficient of polyethylene compared to copper. The major advantage of the polyethylene pipes is, however, the low price compared to the copper pipes.

Relative values of soil moisture were obtained for the two types of pipes, when the relative air moisture was $80 \%$ and significantly higher values were obtained for the copper pipes, when the relative moisture of the air was $60 \%$ (Fig. 3). For example, at the sampling point P2-2 '(Table 3) there was a difference on the average value of 6.1 percent. 


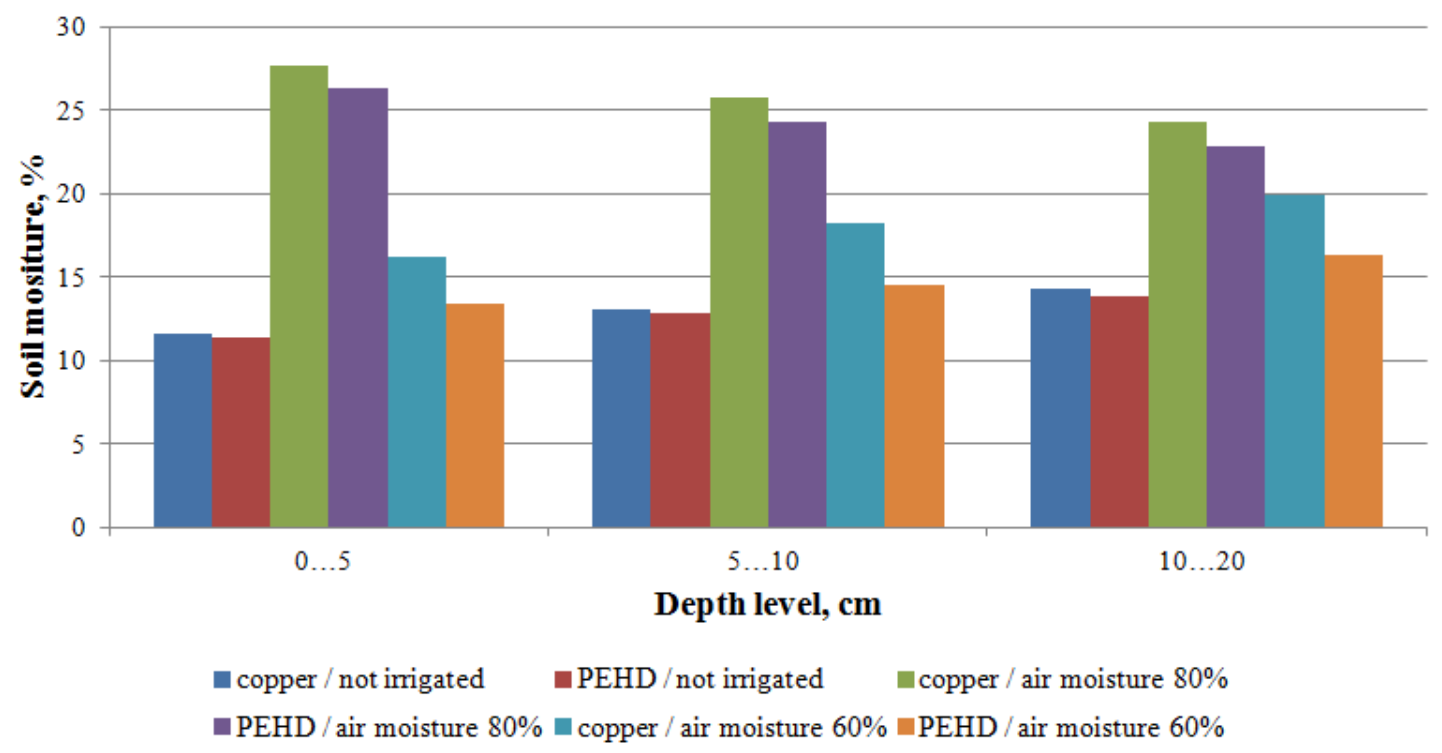

Fig. 3. Variation of soil moisture

\section{Conclusions}

Irrigation by condensation is an inexhaustible resource of water for irrigation, through combination of high air relative moisture, air temperature and the low temperature of water circulating through a closed loop system.

The soil moisture regime on three soil depth levels $(0-5 \mathrm{~cm} ; 5-10 \mathrm{~cm} ; 10-20 \mathrm{~cm})$ and two air relative moisture conditions ( $80 \%$ and $60 \%$ ) for the two types of pipes (copper and PEHD) was compared. Statistical indicators showed that the soil moisture sampling values were homogeneous and also the results for the average of soil moisture on the depth levels and on the sampling points were representative.

The average soil moisture for all sampling points corresponding to the copper pipes was higher than for the PEHD pipes. These differences were significantly higher, when the relative moisture of the air was $60 \%$. This observation is particularly important to prove the efficiency of irrigation by condensation and in periods and areas, when the relative moisture of the air is lower.

The experimental researches in this study highlighted that irrigation by condensation could be a solution for arid and semi-arid areas, where groundwater is deep and fresh water sources are rare. Future research will focus on assessing the impact of condensation irrigation on the soil water reserve.

\section{Acknowledgements}

This work was supported by a grant of the Romanian Ministry of Research and Innovation CCDI - UEFISCDI, Project INNOVATIVE TECHNOLOGIES FOR IRRIGATION OF AGRICULTURAL CROPS IN ARID, SEMIARID AND SUBHUMID-DRY CLIMATE, project number PN-III-P1-1.2PCCDI-2017-0254, contract No. 27PCCDI / 2018 and project PN 191002 01- DEVELOPMENT OF INNOVATIVE TECHNOLOGIES IN SMART FARMS within the Program NUCLEU 2019-2022.

\section{References}

[1] Widegren M. Condensation irrigation, desalination irrigation system. Master thesis 1986:002E, Lulea University of technology, Sweden, 1986.

[2] Ruess K., Federer H. Using sea water for irrigation. The Agricultural Engineer, 45 (4), 1990, pp. 116-117.

[3] Gustafsson A.M., Lindblom J. Underground condensation of humid air - a solar driven system for irrigation and drinking water production. Master thesis: $140 \mathrm{CIV}$, Lulea University of Technology, Sweden, 2001. 
[4] Dillow C. Aussie Airdrop Harvests Moisture From Thin Air. AUSTRALIAN POPULAR SCIENCE, [online][16.02.2019] Available at: http://www.popsci.com.au/science/energy/airdropwhich-harvests-moisture-directly-from-desert-air-wins-james-dyson-award, 2012.

[5] Gertz E., Di Justo P. Environmental Monitoring with Arduino. Published by O'Reilly Media, Inc., United States of America,2012.

[6] Alnaser W.E. , A. Barakat. Use of condensed water vapour from the atmosphere for irrigation in Bahrain. Applied Energy, 65 (1-4), April 2000, pp. 3-18.

[7] Beysens D., Milimouk I., Nikolayev V., Muselli M., Marcillat J. Using radiative cooling to condense atmospheric vapor: a study to improve water yield. Journal of Hydrology, 276 (1-4), 15 May 2003, pp. 1-11.

[8] Tomaszkiewicza M., Abou Najma M., Zuraykb R., El-Fadel M. Dew as an adaptation measure to meet water demand in agriculture and reforestation. Agricultural and Forest Meteorology, vol. 232, 2017, pp. 411-421.

[9] Plesa I., Burchiu V. Exploitation of Land Improvement Systems, Ceres Publishing House, 1986.

[10] Timofti E. Statistics: Theory and Applications. Agrarian State University of Moldova, 2010. 